\title{
Cotton Khadi fabric dyeing with natural dye extracted from the petals of Butea monosperma Flower using different mordants
}

See end of the paper for authors' affiliations Adya Tiwari

Department of Textiles and Apparel Designing, College of Home Science, Maharana Pratap University of Agriculture and Technology, Udaipur (Rajasthan) India

Email : tiwariadya@gmail.com
ABSTRACT : Natural dyes are eco-friendly, biodegradable, non-toxic, and having no side effects on skin as compared to synthetic dyes. These dyes obtained from different natural sources which may be animal and plants sources (like stem, bark, flowers, leafs and roots of the plants). In the present work, dye was extracted from the petals of Butea monosperma flowers were used for natural colouring to cotton Khadi fabric with different concentrations of dye i.e. $10 \%, 20 \%$ and $30 \%$ using five different types of mordant i.e. P. granatum, P. emblika T. bellirica, A. catechu and F. sulfate (Iron (II) sulfate heptahydrate) at three different concentration (5\%, $10 \%$ and $15 \%$ ). Dyed Khadi fabric was evaluated for colour fastness towards washing, rubbing, and sunlight. Cotton Khadi fabric samples dyed with B. monosperma with $30 \%$ concentration of dye and 15 per cent mordants concentration using pre-mordanting method gavegood to excellent wash and rub fastness ratingswith all mordants. P. granatum and T. bellirica mordants with premordanting method using different mordant's concentrations i.e. 5\%, 10\% and 15\% as compare to all other mordants produced moderate fading to no fading against blue dyed standards of 18 rating scale. The dyed samples showed very good colour strength $(\mathrm{K} / \mathrm{S})$ and colourimetric appearance using CIE L* $\mathrm{a}^{*} \mathrm{~b} *$ colour space in terms of colour co-ordinates. The fabric samples mordanted with $P$. granatum gave very good colour strength with all concentrations of dye and mordants as compare to other mordants, respectively. Large ranges of shades were obtained using different types of mordants and their concentrations with petals of Butea monosperma dye.

KEY WORDS: Natural dye, Butea monosperma, Colour fastness, Colour strength, Cotton Khadi fabric

- HOW TO CITE THIS PAPER : Tiwari, Adya and Srivastava, Meenu (2018). Cotton Khadi fabric dyeing with natural dye extracted from the petals of Butea monosperma Flower using different mordants. Asian J. Home Sci., 13 (1) : 187-194, DOI: 10.15740/HAS/AJHS/13.1/187-194. Copyright@ 2018: Hind AgriHorticultural Society. 